\title{
Smoking: A Global Health Peril
}

T his issue includes an article about the smoking patterns of Muslims in New York. Out of the respondents to the survey the authors conducted, $12.8 \%$ were current tobacco users, and $12.3 \%$ reported its prior use. Many reported exposure to second-hand smoking. Of those who were exposed, $55 \%$ received second-hand smoke from family members, $60 \%$ from friends, and $47 \%$ received their exposure at work. Many of the respondents were not familiar with cessation resources or methods. ${ }^{1}$

These data are quite alarming, especially because the survey was carried out in 2009, more than 50 years after the federal government recognized the dangers associated with smoking and responded with multiple steps to educate the populace about the dangers of smoking and instigated several cessation programs. Especially alarming is the high exposure rate of second-hand smoking. The IMANA Public Health Committee issued a position statement on that topic in 2009 , which was published in JIMA. ${ }^{2}$

Cigarette smoking remains the leading cause of preventable mortality and morbidity in the United States. As early as 1989, the U.S. surgeon general estimated that $>400,000$ deaths annually are attributable to smoking. ${ }^{3}$ Several studies corroborated this and documented that these estimates are not substantially altered by adjustments for behavioral and demographic factors associated with smoking. ${ }^{4}$ A more recent report indicates that smoking results in an estimated 443,000 premature deaths and \$193 billion (U.S. dollars) in direct health-care expenditures and productivity losses each year. ${ }^{5}$ The prevalence of smoking among youth and adults has declined in the United States during the last few decades. While its prevalence varies among the different ethnic and racial groups and between men and women, it did decline from an approximate average of 50\% in 1965 to an approximate average of $30 \%$ in 2008.6 Surveys conducted from 2006 to 2008 indicate a current smoking rate that varies by ethnicity and race, age, educational attainment, employment status, poverty status, and sex. The smoking rate was highest (37.8\%) in the 26-34 age group and lowest (9.4\%) in > 65-year-old group. ${ }^{6}$ Along with this decline in the smoking rates, the majority of Americans work and live in smoke-free environments due to public awareness and pressure on local governments to legislate smoke-free ordinances. Many public establishments, and certainly most hospitals, do not allow smoking in their premises.

While the prevalence of tobacco use has declined in United States, it has actually increased in many of the developing countries beginning in the early 1970s. A World Health Organization (WHO) report in 1983 showed that while tobacco consumption fell by 1.1\% a year in developed countries from 1976 to 1980 , it rose by $2.1 \%$ in the developing countries. ${ }^{7}$ In 1995 it was estimated that $82 \%$ of the world's 1.1 billion smokers lived in developing countries. ${ }^{8}$ This increase is attributed at least in part to the aggressive marketing campaigns of the tobacco industry. Faced with the difficult business environment (lawsuits), especially in the United States, and the falling demand for cigarettes in industrialized countries, these multinational tobacco companies fiercely competed to expand sales in the developing countries where they met with little or no opposition from the local governments. ${ }^{9}$

In 1988 WHO reported the prevalence of smoking in many developing countries. In Egypt it was 33\% in adult males and $12 \%$ in adult females. The rates were $52 \%$ and $12 \%$ in Kuwait and $58 \%$ and $6 \%$ in Tunisia, respectively. The corresponding rates in Pakistan were 44 and 16\%, and in Malaysia they were 56 and $12 \% .{ }^{10}$ A more recent study published in 2000 reported the prevalence of smoking in Tunisia to be $52 \%$ in men and 6\% in women. ${ }^{11}$ In Syria, a study published in 2002 reported that the prevalence of current smokers among high school students was $16 \%$ and $7 \%$ for boys and girls, respectively, while in adults the rates were $48 \%$ and $9 \%$ for men and women, respectively.12 A more recent study published in 2005 reported that $34 \%$ of Egyptians are daily smokers. Men had significantly higher rates than women, $43.4 \%$ vs. $4.7 \%$, respectively. ${ }^{13}$ 
WHO attributes 4.9 million deaths worldwide per year to tobacco and predicts that if the current trend continues, deaths will increase to $>10$ million by $2030 .{ }^{14}$ Out of these deaths $70 \%$ will be in the developing world.15 These statistics prompted WHO to negotiate a Framework Convention on Tobacco Control, a global public health treaty that asks countries to implement comprehensive tobacco control programs. ${ }^{16}$ In developing countries, ${ }^{17}$ and in the Middle East spesifically ${ }^{18}$ there have been proposals to curtail smoking rates that are culturally sensitive and adapted to their specific socioeconomic conditions while adopting the universal measures that proved successful in the developed countries. These measures include restrictions on advertising, labeling, increased taxation on tobacco products, and legislation for smoke-free areas.

It is noteworthy that the increasing prevalence of smoking is also evident in Muslim countries, whether or not mentioned above. This is happening despite the Islamic injunction against harming oneself. The Qur'an says:

... [M] ake not your own hands contribute to your destruction ...19

There is now unassailable evidence that smoking, whether it is active or passive, is causally related to disease and death. It is definitely harmful to oneself and the smoker contacts, especially family members. ${ }^{2}$ Muslim scholars have issued many religious edicts declaring that smoking is either harām (forbidden) or at least makrūh (disliked). ${ }^{2}$

While great progress has been achieved in the United States, more work needs to be done. Still many states are not mandating smoke-free restaurants and other public places. Media campaigns need to promote smoke-free homes, as this cannot be mandated by the government. Also, more emphasis needs to be laid on smoking cessation. Long-term cessation rates using current methods continue to be approximately $10 \%$. They are costly and not covered by insurance. Raising taxes on cigarettes contributes to the success of cessation and needs to be continued. ${ }^{20}$ The Federal Family Smoking Prevention and Tobacco Control Act is a step in the right direction. It gives the Federal Drug Administration (FDA) authority to regulate the tobacco industry and its products. It strengthens restrictions on advertisements, requires new and more prominent warning labels, compels companies to disclose all ingredients in tobacco products and authorizes the FDA to restrict harmful additives and to monitor and reduce nicotine yield. ${ }^{21}$ The FDA has to develop protocols for testing toxicity and addictive potential of the different tobacco products. The complexities of these protocols and especially its limitations have been discussed. 20

Finally, it needs to be mentioned that tobacco companies are producing oral tobacco products to replace cigarettes as a means of reducing health risks. An example of such products is snus, a moist snuff that is low in tobacco specific nitrosamines. It has been widely used in Sweden with little increase in the risk of cancer and cardiovascular disease.22 The introduction of "lower risk" products is of concern as it decreases efforts to promote cessation protocols. ${ }^{20}$ These protocols seem to be the most effective in combating the tobacco pandemic.

\section{Hossam E. Fadel, MD, PhD, FACOG \\ Editor-in-Chief, JIMA \\ Maternal Fetal Medicine, University Hospital Clinical Professor \\ Department of Obstetrics and Gynecology \\ Medical College of Georgia \\ Augusta, Georgia \\ HEFadel@gmail.com}

\section{References}

1. Sayeed S. Tobacco use among NYC Muslims: results of the Nafis Salaam Community Survey. J Islam Med Assoc. 2011;43:nn-nn. Available from: http://jima.imana.org/article/view/6053.

2. Haq MM, Sufi A, Haque AK et al. Eliminate secondhand smoking from Islamic campuses in North America. J Islam Med Assoc. 2010;42:97-8.

3. Reducing the health consequences of smoking: 25 years of progress: a report of the Surgeon General. Washington, DC: Centers for Disease Control, National Center for Chronic Disease Prevention and Health Promotion, Office on Smoking and Health; 1989. Available from http://profiles.nlm.nih.gov/NN /B/B/X/S/.

4. Thun MJ, Apicella LF, Henley SJ. Smoking vs other risk factors as the cause of smoking-attributable deaths: confounding in the courtroom. JAMA. 2000;284:706-12. 
5. Centers for Disease Control and Prevention (CDC). Smoking-attributable mortality, years of potential life lost, and productivity losses - United States, 2000-2004. MMWR Morb Mortal Wkly Rep. 2008:57:1226-8. Available from http://www.cdc. gov/mmwr/preview/mmwrhtml/mm5745a3.htm.

6. Garrett BE, Dube SR, Trosclair A, et al. Cigarette smoking - United States, 1965-2008. MMWR Surveill Summ. 2011;60(SU-1):109-13. Available from http://www.cdc.gov/mmwr/preview/mmwrhtml/s u6001a24.htm.

7. World Health Organization. Smoking control strategies in developing countries. Report of a WHO expert committee. Geneva: World Heath Organization; 1983. Available from: http://whqlibdoc.who.int/trs/WHO_TRS_695.pdf.

8. Gajalakshmi CK, Jha P, Ranon K, et al. Global patterns of smoking and smoking-attributable mortality. In: Jha P, Chaloupka, eds. Tobacco control in developing countries. New York: Oxford University Press; 2000:11-39.

9. Joossens L. From public health to international law: possible protocols for inclusion in the Framework Convention on Tobacco Control. Bull World Health Organ. 2000;78:930-7. Available from: http://www.who.int/bulletin/archives/78(7)930.pdf. 10. Crofton J. Tobacco and the third world. Thorax. 1990;45:164-9. Available from: http://www. ncbi.nlm.nih.gov/pmc/articles/PMC462376/.

11. Fakhfakh R, Ben Romdhane H, Hsairi M et al. Tendances de la consommation tabagique en Tunisie. East Mediterr Health J. 2000;6:678-86. Available from: http://www.emro.who.int/publications/emhj/0604/08.htm.

12. Maziak W. Smoking in Syria: profile of a developing Arab country. Int J Tuberc Lung Dis. 2002;6:18391. Available from: http://www.ingentaconnect. $\mathrm{com} /$ content/iuatld/ijtld/2002/00000006/00000003 /art00002.

13. Islam SM, Johnson CA. Influence of known psychosocial smoking risk factors on Egyptian adolescents' cigarette smoking behavior. Health Promot Int. 2005;20:135-45. Available from: http://dx. doi.org/10.1093/heapro/dah604.

14. Satcher D. Why we need an international agreement on tobacco control. 2001;91:191-3. Available from: http://www.ncbi.nlm.nih.gov/pmc/articles /PMC1446526/.

15. World Health Organization. Leave the pack alone. 1999. Available from: http://www.forcesnl.org/WHO/ADVISORY98.PDF.

16. World Health Organization. WHO Framework Convention on Tobacco Control. Available from http://www.who.int/fctc/en/.

17. Abdullah ASM, Husten CG. Promotion of smoking cessation in developing countries: a framework for urgent public health interventions. Thorax. 2004;59:623-30. Available from: http://dx.doi. org/10.1136/thx.2003.018820.

18. Maziak W, Eissenberg T, Klesges RC, et al. Adapating smoking cessation interventions for developing countries: a model for the Middle East. Int J Tuberc Lung Dis. 2004;8:403-13. Available from: http://www.ingentaconnect.com/content/iuatld/ijt ld/2004/00000008/00000004/art00003.

19. The Glorious Qur'an, Chapter 2, Verse 195.

20. Samet JM, Wipfli H. Unfinished business in Tobacco control. JAMA. 2009;302:681-2.

21. Family smoking prevention and tobacco control and federal retirement reform. (Public Law 111-31) Available from: http://frwebgate.access.gpo. gov/cgi-bin/getdoc.cgi? db na me $=111$ _cong_public_laws\&docid=f:publ031.111.pdf.

22. Roosaar A, Johansson AL, Sandborgh-Englund G, et al. Cancer and mortality among users and nonusers of snus. Int J Cancer. 2008;123:168-73. 